Bol. Acad. peru. leng. 54. 2012 (237-251)

\title{
EL PERÚ, LOS PERUANOS Y TRES CARTAS INÉDITAS DE VALLEJO
}

\author{
Jesús Cabel \\ Academia Peruana de la Lengua
}

Fecha de recepción: $\quad$ 21/09/2012

Fecha de aceptación: $\quad$ 10/10/2012

Si nos preguntáramos por el concepto del Perú y los peruanos que tenía César Vallejo, en París, vamos a constatar a lo largo de su correspondencia que la respuesta no es tan alentadora como quisiéramos, pues palpita en él un resentimiento a flor de labios. Sin embargo, en la comunicación que sostendrá con los poetas y escritores peruanos, a propósito de la edición de los libros de aquellos, se opera en él un cambio total; hay un tono celebratorio, fraternal y de adhesión espiritual permanentes. Así puede advertirse en las cartas dirigidas a los poetas José María Eguren (al único que le escribe desde Trujillo, durante su estancia en el Perú), Emilio Armaza, Rafael Méndez Dorich y Juan Luis Velásquez; así como a los escritores Antenor Orrego, José Carlos Mariátegui y Luis Alberto Sánchez.

Se ha escrito con justeza ${ }^{1}$, que a partir de estas cartas pueden hallarse las claves de los criterios poéticos y estéticos de Vallejo, que

1 SOBREVILLA, David. César Vallejo poeta nacional y universal y otros trabajos vallejianos. Lima: Amaru Editores, 1994, p. 207. Revísese su utilísimo libro: Introducción bibliográfica a César Vallejo. Lima: Amaru Editores, 1995, p. 143. 
devendrán luego en la posición de este acerca del compromiso del escritor. Precisamente, el año 1926, que lo sorprende enfermo ${ }^{2}$, coedita con Juan Larrea la revista Favorables, París, Poema y empieza a interesarse por la política, a partir del proyecto de edición de la revista Foro. Este es el año que va a contactarse epistolarmente con los poetas Alejandro Peralta, Alcides Spelucín y Emilio Armaza.

Alejandro Peralta (así como su hermano Arturo Peralta) fue uno de los ejes centrales, al lado del talentoso Gamaliel Churata ${ }^{3}$, del movimiento cultural Orkopata, en cuyo trajinar lo encontramos vinculado a los primeros voceros indigenistas: Boletín Kuntur y Vórtice (Sicuani), Atusparia (Huaraz), Chiripu y Waraka (Arequipa), Inty (Huancayo), La Sierra y La Región (Lima), Puna (Ayaviri) y Boletín Titikaka (Puno), alentados por la célebre revista Amauta de José Carlos Mariátegui. Referente a Ande de Peralta, hallamos que el indio en su poesía no es un personaje novelesco ni de ficción, es el autor de un drama cuyo discurrir tiene como telón de fondo la realidad violenta y heterogénea del medio, donde hasta la esperanza, como señalara en cierta oportunidad Manuel González Prada, se le está extirpando. Por eso, Vallejo le escribe: "Siga usted por su vía. Puede estar seguro de que sus poemas quedarán. Son ellos de los versos que andan y viven. Lo demás está en los estantes y eso nos tiene sin cuidado" ${ }^{4}$.

Por cierto que no se equivocó. Otro que perteneció a ese gran movimiento cultural sureño, fue Emilio Armaza, a quien le acusa recibo del libro Falo, en los términos siguientes:

2 COYNÉ, André. César Vallejo. Buenos Aires: Ediciones Nueva Visión, 1968, p. 275. Revísese su: Medio siglo con Vallejo. Lima: Pontificia Universidad Católica del Perú, 1999, p. 728.

3 Gamaliel Churata no solo fue el organizador del movimiento cultural Orkopata sino también el director de Editorial Titikaka / Boletín, su órgano de expresión, en el que puede verificarse la gran acogida que tuviera el libro Ande de Alejandro Peralta.

4 Editorial Titikaka / Boletín. Puno, septiembre, 1926, pp. 12-13. En 1997, Dante Cúneo y Juan Alberto Osorio han realizado una edición facsimilar de este boletín, que comprende los veinticuatro primeros números. 
Su libro Falo responde a esta exigencia fundamental de la vida y del arte. Fuera de este mérito verdaderamente excepcional en estos tiempos, sus versos respiran peruanidad, es decir, humanidad, por anchos y salubres pulmones titikakas. La paja de la jalca vibra en Falo, contra el ventisquero y a favor de la dicha de cancha y cal domésticas. iQué bellas estrofas que revientan blanco, blanco! ${ }^{5}$

A Spelucín ${ }^{6}$, que no solo es el compañero integrante de ese movimiento norteño tan importante e injustamente silenciado, llamado Grupo Norte — del que él también es uno de sus más ilustres integrantes- , sino del que guarda la hermandad más sincera y solidaria, le escribe refiriéndose a El libro de la Nave Dorada:

Tu libro es un libro maestro, que servirá de guía espiritual a los mozos de América. Creo que no hay precedente en el continente de una obra primigenia de tanto dominio en la técnica y de tan acabada maestría verbal. Tu libro es una obra clásica en el sentido de perfección de la palabra ${ }^{7}$.

En febrero de 1928 escribe a Rafael Méndez Dorich: "He leído tus poemas y sé que hay en ti un poeta cazador de tiempo y poesía limpia. Insiste, persiste y verás que las palabras llegan cuando se les llama muy temprano (...)"

En ese mismo año, envía una carta a José Varallanos, desde Moscú, disculpándose de no haberlo hecho antes, pues ha estado fuera de París. Escribe: "Ahora lo hago felicitándolo por el coraje de su estética y por los reales granos de buena poesía, que hay en su obra"

5 Epistolario general, pp. 131-132.

6 Alcides Spelucín le ha dedicado el libro Contribución al conocimiento de César Vallejo. Trujillo: Ediciones SEA, 1989, 106 pp., cuyo texto apareció en Aula Vallejo, II, 2,3-4. Córdoba: 1963.

7 RIBERO-AYLLÓN, Teodoro. Spelucín, poeta del mar. Trujillo: Trilce Editores, 1996, p. 125.

8 AYALA, José Luis. El cholo Vallejo. Lima: Editorial FIMART S. A., 1994, pp. 106-107.

9 Epistolario general, p. 186. Vallejo se refiere al libro: El hombre del Ande que asesinó su esperanza. 
Expresiones de esta naturaleza las encontraremos en la misiva dirigida a Nazario Chávez Aliaga, en relación a su libro Parábolas del Ande.

No sé la edad civil en que usted ha escrito sus poemas, que denuncian una edad espiritual verdaderamente madura. Reposada cesura de período, desarrollo procesional y tranquilo de la alegría y del dolor, discurso doctrinal sin disgresión ni aparato, solidez casi clásica del espinazo que ama y odia y del carpo que avanza y permanece. Proclama de bastos, arenga de copas, cada poema suyo emborracha y aporrea, tunde en la historia, apasiona en el instante ${ }^{10}$.

De estas misivas dirigidas expresamente a los poetas, hay que rescatar no solo la cordialidad de Vallejo para responder u opinar, sino también su preocupación por dar a conocer en París lo que estos producían, convirtiéndose así en el difusor y promotor secreto de los poetas peruanos y sus libros. Como puede apreciarse, no adopta posturas para alentarlos a que continúen escribiendo ni escatima esfuerzos para mostrar su admiración por ellos. Vallejo es transparente, humano, sensible y, sobre todo, poeta.

Otro de los grandes amigos de César Vallejo fue, indiscutiblemente, el poeta Juan Luis Velásquez ${ }^{11}$, el inolvidable autor de El perfil de frente (1924), quien desde su llegada a París en los primeros días de febrero de 1927, es recibido por Vallejo con la fraternidad del hermano mayor, considerando que este era once años mayor que aquel. En una de las cartas, específicamente la de 1936, que es cuando Velásquez se encuentra nuevamente en Lima, Vallejo muestra en reiteradas oportunidades su preocupación por la vida política y cultural del país, así como su deseo de "volver cuanto antes al Perú"12, y en la última carta que le escribiera a Juan Luis, del 31 de mayo de 1937, le confirma: "He leído tus poemas

10 CHÁVEZ ALIAGA, Nazario. Autobiografía. Lima: Talleres Gráficos de la Librería Editorial Minerva, 1973, p. 402.

11 Léase el excelente libro: Juan Luis: el poeta incomunicado. Lima: Edición de la Asociación Cultural El Último Jueves, 1995, 89 pp. Fue escrito por el poeta, ensayista y maestro universitario Manuel Velásquez Rojas, hijo del insigne poeta piurano.

12 VELÁSQUEZ ROJAS, Manuel. Ojos de venado. Lima: Ediciones Perú Joven, 1990, p. 46. 
con el fraternal interés que todo lo que haces me despierta. Ardo en ganas de ver el conjunto de tu producto intelectual"13.

En esa misma carta, Vallejo sostendrá: "A mi modo de ver, todo el secreto del destino social del escritor sobre todo, está en eso: en saber a ciencia cierta lo que quiere y puede hacer. Definido este enunciado previo, lo demás viene por añadidura"14.

Gran parte de estas preocupaciones, que tienen que ver, incluso, con su decisión personal como poeta, en cuanto a la publicación de sus poemas, pueden encontrarse también en las cartas dirigidas a Luis Alberto Sánchez. En una de ellas, le escribe: "Me admira de veras su tenaz e inteligente actividad. He leído y leo siempre, con el cariño más fraternal, cuanto escribe usted: sus libros, sus crónicas y ensayos. Palpita en todos ellos una creciente inquietud y una capacidad visual y reflexiva extraordinaria en el Perú"15.

En otra misiva, le expresará a Sánchez que es lamentable que no asista al Segundo Congreso Internacional de Escritores para la Defensa de la Cultura, pero “(...) tu nombre queda siempre vinculado a los trabajos y a las conclusiones del Congreso. Sabemos que estás con la causa mundial de la cultura, viejo defensor como eres de sus más puros destinos en nuestra América"16; y en una última carta del 10 de enero de 1938, le manifiesta que, de acuerdo a las instrucciones de Orrego y Spelucín, han "iniciado aquí los trabajos encaminados al desarrollo de una enérgica campaña por las libertades en el Perú”17.

Es conveniente, por otro lado, tener una idea de lo que sucedía en nuestro país en el lapso epistolar de Vallejo con los poetas peruanos.

\footnotetext{
13 Epistolario general, p. 269.

14 Ibídem, p. 269.

15 Ibídem, p. 212.

16 Ibidem, p. 272.

17 Ibídem, p. 273.
}

Bol. Acad. peru. leng. 54(54), 2012 
Empezó entonces [escribe el maestro Núñez] una etapa desoladora en la cultura del país, una especie de colapso cultural. Además de que no aparecían revistas culturales y los periódicos habían suprimido suplementos de esa índole, estaban cerradas las salas de conferencias, las instituciones asimismo en crisis, no funcionaban galerías de arte o salas de conciertos, y entre otras realidades como la restricción de la importación de libros, se habían clausurado varias universidades del Estado. Solo subsistía en Lima una universidad particular. La depresión era general y la vida intelectual paralizada ${ }^{18}$.

Como podrá deducirse, entre la etapa convulsa europea que soportaba Vallejo y la anárquica que se imponía en nuestro medio, ¿qué esperaba?

En el alma de Vallejo [continúa el maestro Núñez] se abría otro frente de angustia y desazón. El Perú y España se habían convertido en dos campos divergentes dentro de la inquietud social de Vallejo. El poeta quedaba sin asidero en su normalidad anímica. Antiguos proyectos de seguir viviendo en España o regresar al Perú dejaban de tener sentido ${ }^{19}$.

Estas misivas, concluimos, no solo prueban el gran respeto que Vallejo sentía por la obra de los poetas y escritores peruanos - las cartas a Orrego y Mariátegui son pruebas irrefutables-, y su evolución como poeta inmerso ya en problemas políticos, adscrito al partido Comunista, sino también y fundamentalmente, su gran preocupación y solidaridad ${ }^{20}$ por nuestro país, del que sin duda sintió, padeció y vivió en lo más hondo de su vida y de su obra, tal como lo ha señalado Américo Ferrari:

18 Ibídem, p. 273.

19 NÚÑEZ, Estuardo. "Vallejo y el Perú: los difíciles años treinta". En: Ricardo González Vigil (editor). Intensidad y altura de César Vallejo. Lima: Pontificia Universidad Católica del Perú, 1993, pp. 59-61.

20 Nadia Podleskis Feiss en "La solidaridad en la poesía de César Vallejo" postula que "la solidaridad plena implica una idea de comunidad" y que esta posición que asume Vallejo es "cuando ya había asumido la ideología comunista". En: César Vallejo/Varios. Lima: Universidad Ricardo Palma, 1994, p 127. 
Tres criterios podrían servir de hilos conductores para rastrear la presencia del Perú en esta poesía: el lenguaje del poeta, la temática nuclear de cierto número de poemas, y las alusiones o referencias al Perú o a aspectos, gentes y cosas de la tierra dispersa a todo lo largo de la obra, que no constituyen forzosamente el tema central de un poema, pero que por eso mismo, por incrustarse sorpresivamente en un texto que a veces habla de otra cosa, como fragmentos de nostalgia, de pesadumbre o de esperanza proyectados desde lejos, poseen un fuerte valor referencial ${ }^{21}$.

Concluye Ferrari: "El Perú es ya totalmente del mundo y su presencia en esta poesía es realmente universal" ${ }^{22}$.

En estas tres cartas (inéditas hasta la fecha), Vallejo se dirige al insigne historiador Luis E. Valcárcel, autor no solo de la Historia del Perú Antiguo sino de la Ruta cultural del Perú, libro tan leído como Siete ensayos de interpretación de la realidad peruana, de José Carlos Mariátegui, el editor también de su Tempestad en los andes; cabe señalar que estas obras son claves para entender mejor al Perú de ayer y de siempre. En estas cartas, Vallejo reafirma su fe por los trances (pasados y presentes) de su raza que están ligados a la arqueología e historia, solidarizándose "plenamente con sus esfuerzos al servicio de los valores y derroteros indígenas de nuestro pueblo".

Si consideramos que la última misiva escrita por Vallejo fue dirigida a Luis José de Orbegoso, el 15 de marzo de 1938 y que posteriormente no se conocen otras de fechas posteriores, la dirigida a Luis E. Valcárcel el 2 de febrero de 1938 es la penúltima que en vida redactó el poeta. Aquí se vuelve al viejo tema del regreso al Perú, tantas veces frustrado por diferentes circunstancias, en este caso resulta revelador que él mismo concluya: "A juzgar por el fracaso de la persona encargada de gestionar mi pasaje", presentándose como alternativa el nuevo proyecto de publicar

21 FERRARI, Américo: "El Perú en la poesía de César Vallejo", pp. 77-86. En: Roland Forgues (editor). César Vallejo / Vida y obra. Lima: Amaru Editores, 1924, 211 pp.

22 Ibídem.

Bol. Acad. peru. leng. 54(54), 2012 
una revista "sin esperar mi llegada a Lima". Proyecto que, finalmente, no se realizará por la inexplicable desaparición física del poeta pero que nos deja una gran lección de amor, vocación y solidaridad con el Perú, los peruanos y su historia.

París, 15 marzo 1936

Querido compañero:

Correspondo a sus noticias de 6 de enero último, y le agradezco inmensamente los folletos y revistas que se ha servido usted enviarme.

Me doy cuenta de la lucha que debe usted sostener allí con las tinieblas y concupiscencia criollas, para llevar a cabo la empresa nacionalista de verdad en que está usted empeñado. Todos los légamos de que me habla usted, los conozco. Admiro, por eso, su tesón y su energía, para no huir para siempre, como usted dice, de ese mundo emponzoñado. iY estoy seguro de que no huirá usted! Yo me solidarizo plenamente con sus esfuerzos al servicio de los valores y derroteros indígenas de nuestro pueblo. El interés que siento por un tal empeño procede de una convicción tanto más entrañablemente humana, cuanto que esta se apoya, me parece, sobre conclusiones científicas de curso universal y corriente en nuestros días y que ya solo unos pocos reaccionarios recalcitrantes o interesados, continúan negando o discutiendo.

Mándeme su próximo libro y todo cuanto cree usted que puede interesarme sobre nuestra historia y nuestra raza. Pienso dar algunas cosas suyas al francés, pero hacen falta fotos para los periódicos. Trate de enviarme todas las que pueda.

Las dos manos cordiales de su amigo.

César Vallejo 
París, 7 diciembre 1935

Querido compañero:

Sigo con un cordial y vivo interés su labor a la cabeza del Museo Nacional de Lima, de sus penetrantes artículos y comentarios sobre nuestra arqueología y nuestra historia. Alguna vez he citado su nombre en algún artículo mío publicado en un periódico de París. En fin, me intereso entrañablemente por los trances, pasados y presentes, de mi raza: demás está decirle que me siento ligado, también entrañablemente, a los esfuerzos de recreación nacional de todos los que, como usted, ven en nuestra tradición secular y en la carne viva de los Andes, uno de los principales trampolines de un Perú que vendrá.

Mándeme sus artículos. Mándeme su revista del Museo. Mándeme lo que estime y me pueda hacer aquí la propaganda de nuestra historia y arqueología. Yo haré aquí lo que pueda, coordinándome con ustedes. Puede usted dirigir sus cartas a la Legación del Perú en París.

Un apretón de manos.

César Vallejo

Me olvidaba: mándeme noticias, documentos, fotos y estudios traducibles al francés. 
París, 2 de febrero 1938

Querido compañero:

Con ansiedad esperaba sus noticias, que, al fin, he recibido hace tres días.

Le agradezco cuanto me comunica en lo que toca a mi proyectado viaje al Perú, viaje que, a juzgar por el fracaso de la persona encargada de gestionar mi pasaje, creo que se verá postergado por algunos meses.

Lo felicito por su viaje al Uruguay. De todos modos, él le proporciona ocasión de propagar los valores vernáculos de nuestra historia, que es la historia de América. Los ajetreos y cansancios de la travesía están compensados con el precioso fin de ese cursillo.

Tomo nota de lo que me dice usted sobre la situación peruana en orden a la coyuntura internacional. Sus informes me han despejado más de una incógnita al respecto.

En lo que concierne a nuestra revista en perspectiva, sus noticias son, igualmente, muy estimulantes. A este propósito, me parece que, dada la dificultad que por ahora se presenta para realizar mi viaje, convendría afrontar la publicación de la revista inmediatamente y sin esperar mi llegada a Lima. Es decir, creo que usted y Barrantes Castro podrían publicarla de acuerdo con los grandes lineamientos planeados con usted aquí y sobre la base de mi cooperación desde aquí. Más aún: de París, podría yo colaborar con ustedes en forma, en cierto modo más útil, sirviéndonos del correo aéreo. Un material enorme, fresco y bien escogido tendría de esta manera, la revista. En suma, este procedimiento me parece, en principio, por ahora, susceptible de ser, por lo menos, estudiado. Contésteme lo que ustedes piensan, pero cuanto antes.

Hablando con Tristan Tzara, se me ocurre que un viaje de este amigo a América, podría sernos útil, desde el punto de vista de las ideas universales que nos son comunes. Le ruego, por eso, tentar con la dirección de la Universidad de Montevideo, que Tzara sea invitado para un ciclo de conferencias en ese claustro. De allí, Tzara pasaría a Buenos Aires y luego a Chile, al Perú, Ecuador, Colombia y Cuba. Naturalmente, la gestión 
personal de usted habría que hacerla aprovechando su permanencia en Montevideo, a fin de ganar tiempo. Ojalá me conteste usted pronto sobre el particular y con buenas noticias. Sobre la personalidad de Tzara, creo que sería obvio que usted insista cerca de la Universidad uruguaya, dado que se trata de uno de los escritores de mayor irradiación mundial en estos momentos.

Me promete usted escribirme de Buenos Aires. Espero estas noticias con vivo interés. Yo volveré a escribirle ya a Lima.

En cuanto a lo que le digo sobre la revista, todo es cuestión de ponerse de acuerdo. Esto, mientras se posibilite mi viaje, desde luego.

Cumplí con su encargo para González.

Si ve usted a Muelle, dele muchos recuerdos de mi parte.

¿Qué piensa Beltroy sobre todas las cuestiones que nos interesan y de las cuales hemos hablado en París?

Mi señora corresponde afectuosamente sus atentos saludos y, en espera de sus nuevas cartas, le abraza fraternalmente su amigo y compañero.

César Vallejo 


\section{Sren is comprain:}

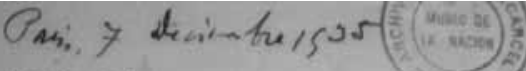

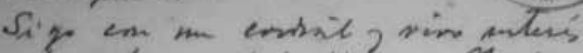

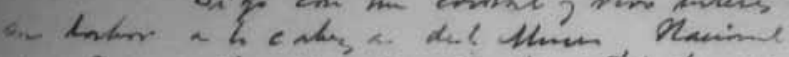

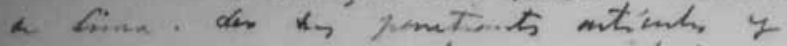

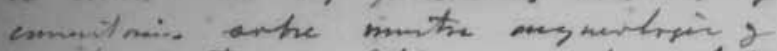

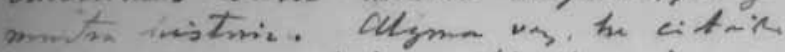

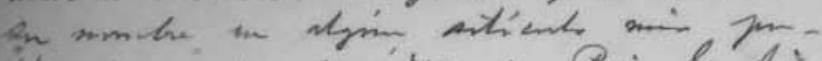

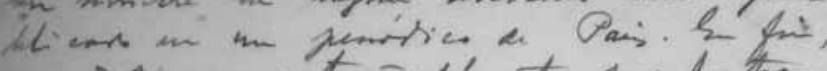

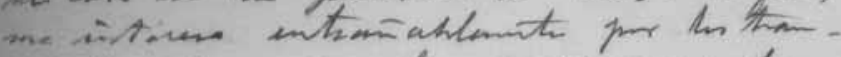

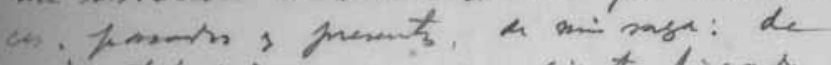

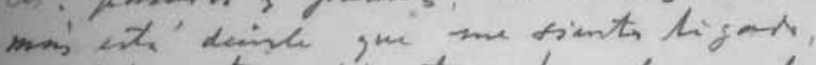

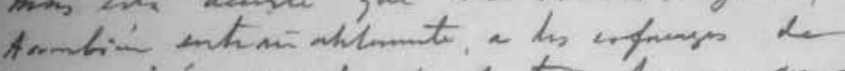

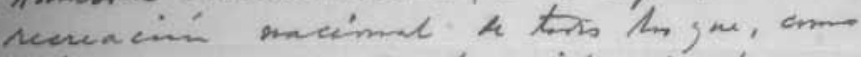

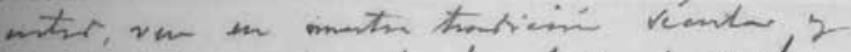

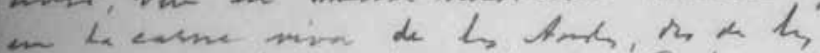
prinicipals traipations de rem Peni jue rentin.

Mintme vas athients. Nimine.

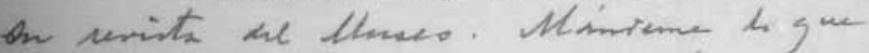

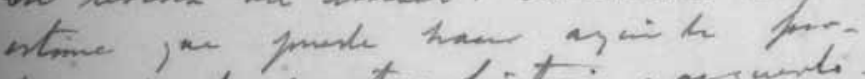

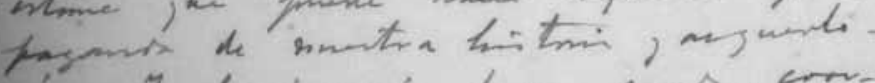

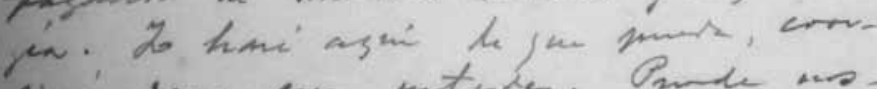

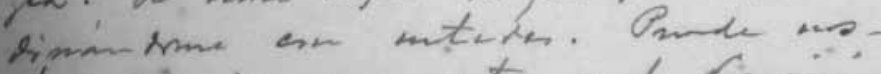
ter hivive Ans cants a he deswin de Penim Pani. Na Un apretin $\angle$ soms.

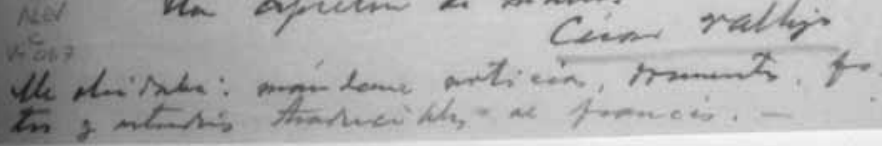




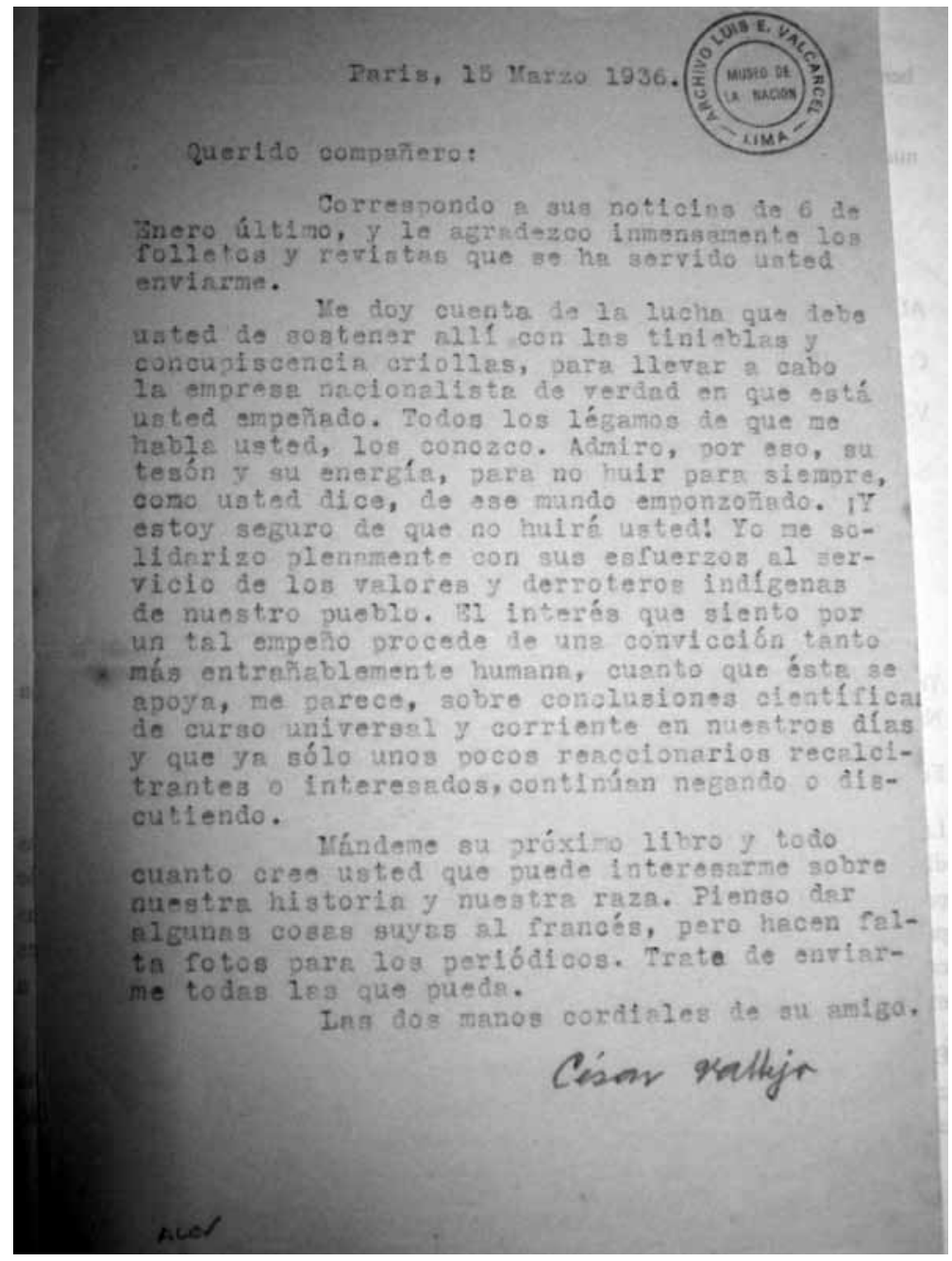

Bol. Acad. peru. leng. 54(54), 2012 
Parli, 2 de Pebrero 1938.

Qu arido compan̂ero:

Con ansiedad esperaba aus noticisa, que, al fin, he recibido hoos tres dias,

I e ngredezoo cuanto me comunien en 10 que tocr a mi proyectedo rieje al Perú, viaje que, a Juapar por el grecaso de la persone encarbade de reationar mi paseje, creo que se verd postergado nor el gunos meses.

Lo felicito por su viaje el Uruguey. De todos modos, 6́l le proporciona ocasión de propagar los velores pornéculos de nuestre hiatorla, que es la historia de Amb́rica.Ios a.fetreos y cansancios de la travesfo estín compensados con el preciosn fin de ese cursilio. Tomo nota de 10 que me dice usted sobre in gituación peruene en orden $\mathrm{B}$ is coyunture internacional. Sus informes me han des. Dejado més de una incógnita al reapecto.

in 10 que concierne \& nuestra revista en perspectiva, sus notioiss son, igualmente, buy estimulantes. A este propbsito, pe parece que, dada la dificultad que por ahora se presente pare reallzar mi vieje, convendrfa afrontar la publicación de 7 a revista inmediatemente y sin esperar mi liegeda e Iima. Bs decir, crea que usted y Barrantes Castro podrín publionrle de acuerdo con los grendes lineamientos plnneados con usted rguf y sobre la base de mi cooperactón desde equi. Jís eun: de Faris, podrf́a yo colnborer con ustedes en forma, en cierto modo més atil, sirviéndonos del correo eảreo. Un material enome, fresco y bien escopido, tendría, de esta manera, la revista. Thn sume, este proceds Inj ento me parece, en prinospio, por ahore, suscep thble de ser, por 10 menos, estudiado. Contésteme lo que ustedes piensan. Pero cuanto antes. Hablando con Tristan Tzara, se me ogurre que un viaje de este amigof a América, podría aernos muy lit 11 , desde el punto de vista do las fdeas unfveranles que nos son comunes. Le ruego, pox eso, tentar con $2 \mathrm{n}$ direcolón de 28 . U. 


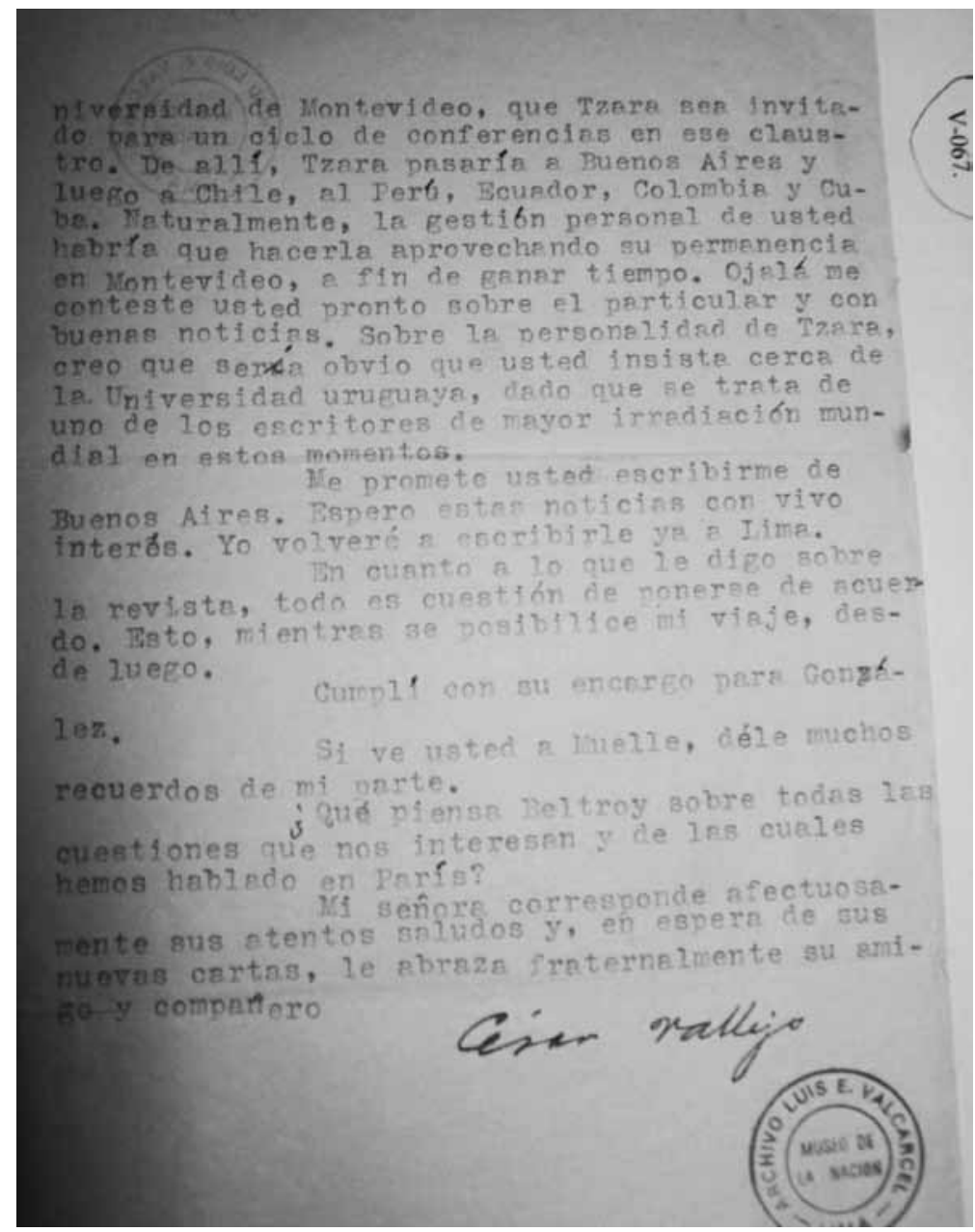

\section{Correspondencia:}

\section{Jesús Cabel}

Miembro correspondiente de la Academia Peruana de la Lengua.

Correo electrónico: jcabel_27@yahoo.com.pe 